\title{
Heads and tails
}

\section{How a visit to the home of structural biology inspired a young scientist.}

\section{Mitsuhiro Yanagida}

first visited Cambridge in June 1968 to attend the International Symposium on Interactions Between Subunits of Biological Macromolecules. It was an excellent meeting, with talks by prominent researchers - I was particularly pleased to hear Francis Crick, who often led the discussions. A mere eight months before this meeting, I had joined Eduard Kellenberger's group at the Institute of Molecular Biology in the University of Geneva, Switzerland. Eduard saved me from being a graduate student in University of Tokyo - the riots in Japanese universities erupted soon after I joined him, and many of my generation were unable to continue their studies.

My work involved using phage morphogenesis as a model for more complex biological structures. My first project was to use an optical diffractometer to analyse the images of electron micrographs showing the tubular 'polyheads' produced in bacteria that were infected with phage T4 mutants. The polyhead was an ideal structure to study with the diffraction analyses of electron micrographs, a technique developed by Aaron Klug in the Laboratory of Molecular Biology (LMB), Cambridge. Although electron microscopy had a theoretical resolution at the atomic level, actual micrographs of biological specimens rarely achieved this because of deformation, damage, noise and the superimposition of images at different focal planes. However, if the biological particles consisted of regularly repeated structures, diffraction analysis could be a powerful tool for obtaining information from the average lattice structure. Another technique, optical filtration, also enabled selection for the side image of helical structures. I inherited the polyhead project from another student, who had left to become an activist for the independence of Jura. In retrospect, social unrest was responsible for two lucky events in my early scientific career.

I obtained a large number of diffraction patterns from polyhead electron micrographs. It seemed clear to me that the polyhead was not the precursor of the normal T4 head shell, as its lattice structure was polymorphic; the polyhead was therefore probably an abnormal assembly. I gave a short talk on these findings at a specialist workshop organized by Aaron after the main symposium. He told me that David DeRosier had found the same things in his laboratory, but that my micrographs might be good enough for further analysis by the optical-filtration method. Although Aaron had already pioneered the

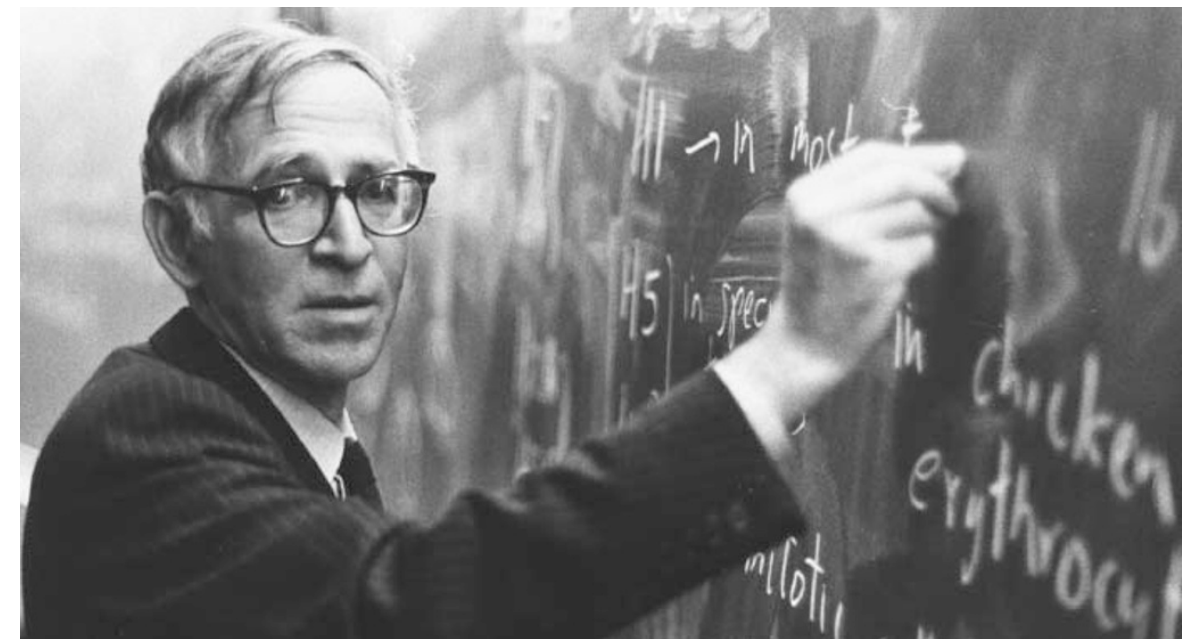

The enthusiasm of Nobel prizewinner Aaron Klug added to the unique atmosphere at Cambridge.

computational Fourier reconstruction for the three-dimensional phage tail structure from electron micrographs, he was still interested in studying the head-related structures by manual diffraction methods.

Aaron and Eduard decided to submit an application for a short-term European Molecular Biology Organization (EMBO) fellowship, which would enable me to work at the LMB for a few months, and I arrived there on a cold, rainy day in December 1968. The laboratory had been established in 1962 by the UK Medical Research Council, following the pioneering work in Cambridge of the previous decade - which included the discovery of the structure of DNA by Watson and Crick. Many of the staff (Max Perutz, Crick and Fred Sanger) were already Nobel laureates and others would soon follow.

On the first day, I was nervous and afraid that I might not understand what Aaron would talk about. From his famous papers on the X-ray crystal analysis of tobacco mosaic virus (initially working with Rosalind Franklin), the quasi-equivalent bonding in the icosahedral virus shell (with Don Caspar) and helical diffraction theory (with Crick), I was convinced that he was a theoretical physicist. I was concerned that with my poor knowledge of diffraction theory, I might be asked to return to Geneva immediately.

To my great surprise, Aaron was interested in experimental details and interpretations, and spent most of the time talking about how to get a clue or a starting point for determining the assembly mechanism of $\mathrm{T} 4$ head proteins. I was relieved to find myself discussing ideas with him. He was an extremely good physics teacher, and a fantastic experimentalist. He had the amazing ability to analyse details of various images by eye, and was able to uncover so many things from raw data. Aaron also spoke of his broad interests in science - beside those of the principal projects of his group. It is no wonder that he was later successful in elucidating the structures of transfer RNA, the nucleosome and the zinc-finger transcription factor, among others. I did not realize at the time, but he had already completed the studies for which he would get a Nobel Prize. Through Aaron's ability and interest, I understood for the first time the depth and strength of structural molecular biology at the LMB. My stay was over all too soon, but by then we had produced several very beautiful filtered images of polyheads.

By merely breathing the air of the LMB, something ultimately changed in my mind and flesh. Everywhere, the spirit of freedom in scientific thinking prevailed — in the seminar room, cafeteria and even the corridors. People there simply exchanged scientific ideas on equal terms. The LMB looked to me like a paradise for the élite scientists who worked there. A second short visit to Cambridge later strengthened this feeling.

I began to have an increasing affinity for British ideas on philosophy, science and life. In my short time working with Aaron at the LMB, I was inspired to make a career as a scientist. However, it took six more years and my own tiny research group in Kyoto University to determine how the three distinct subunits were arranged to form the normal T4 head shell. After that peak of excitement, and a brief intermission with the visualization of single DNA molecules in solution, I encountered the fission-yeast chromosome - which was to be my playground for next 25 years.

Mitsuhiro Yanagida is at the Graduate School of Biostudies, Kyoto University, Yoshida-Honmachi, Kyoto 606-8501, Japan. 